\title{
The impacts of minimum wage on employers' employment strategies and employees' behaviour in Malaysia's hospitality industry: A pitch
}

\author{
Kun Hing Yong a,1 \\ ${ }^{\text {a }}$ University of Queensland, Australia
}

\begin{abstract}
This pitch letter summarizes my personal reflections of employing the pitching research template created by Faff $(2015,2018)$ to my $\mathrm{PhD}$ research topic. It explains how the template guides the author to articulate and conceptualize a research idea critically, clearly, systematically and effectively. Specifically, this letter positively supports the use of the pitching research template, in particular for new $\mathrm{PhD}$ student or novice researcher during their early stage of research process.
\end{abstract}

Keywords: Pitching research; minimum wage; employment strategies; employees' behavior; hospitality

JEL codes: J21; J38; L83

\section{Introduction}

This letter deliberates about my personal experience of employing the pitching research template developed by Faff (2018) to my $\mathrm{PhD}$ research topic - "The impacts of minimum wage on employers' employment strategies and employees' behavior in Malaysia's hospitality industry". I am currently a first year full-time $\mathrm{PhD}$ student enrolled in January, 2018 at the Business School, University of Queensland (UQ). At the initial stage of my $\mathrm{PhD}$ program, the process of searching and identifying an

${ }^{1}$ Corresponding authors: UQ Business School, University of Queensland; Colin Clark, 39, Blair Drive, St. Lucia, Qld, 4072, Australia; tel. (+61) 73346 8100, email address:

k.yong@business.uq.edu.au 
ideal research topic was tough, and I felt like looking for a needle in a haystack. Fortunately, my both supervisors, Associate Professor Richard Robinson and Associate Professor David Solnet encouraged me to enroll the PhD Course "The Research Process in Business"-RBUS6914 in the second term of year 2018. I felt honored when I was introduced to the pitching research template by the template creator himself- Professor Robert Faff or 'Pitch Doctor', during the RBU6914 course. Importantly, being a new $\mathrm{PhD}$ student, the template has guided me into a more systematic way of organizing and evaluating, articulating and arguing, and reshaping my research plan. Indeed, at the end of this course, I absolutely agree with both of my supervisors' opinion that this course is like a "brick and mortar" to the foundation for my $\mathrm{PhD}$ thesis. As the course is structured in a way for $\mathrm{PhD}$ students to acquaint themselves in a research environment, and to develop their skills to find a topic for preparing their $\mathrm{PhD}$ candidature confirmation's document and also publication.

The remainder of this letter will be presented as follows: Section 2 offers a brief review on the utilization of the pitch template. Section 3 deliberates on the reflections of my pitch template application, and Section 4, concludes with my thoughts on this pitching process.

\section{Brief review on the application of the pitch template}

The completed pitching research template developed by Faff (2018) is appended as Appendix 1, presents a simple but clear, informative, systematic and structure to my research topic about "The impacts of minimum wage on employers' employment strategies and employees' behavior in Malaysia's hospitality industry". Interestingly, like many other pitching research template users (Brenner, 2016; Rad, 2016), my completion of the template does not follow the sequence as structured in the pitching research template. My research motivation/puzzle in Item (D) is sparked by the importance of the relatively new event (minimum wage in Malaysia's context) to the research. The appropriate timing to assess the outcome, and the research gap in the literature. Hot debates arise regarding the impacts or potential impacts to business activities following implementation of the Malaysia's Minimum Wage Order 2012 (referred to national minimum wage policy hereafter), incremented in 2016 and the latest scheduled hike in early 2019. The minimum wage hike is anticipated to exert a significant impact on competitiveness of business activities and the labor market. As the national minimum wage policy is considered relatively recent, lack of empirical research has been conducted in this field in the Malaysian context. Furthermore, it would be timely to evaluate the outcome of the minimum wage policy after a few years of implementation, in particular to what extent the targeted objectives have been achieved. 
Consequently, this motivates me to investigate how does the labor-intensive industry such as the hospitality industry, with relatively less room to change production strategy, compare to the manufacturing industry, in regards to the national minimum wage hike. How does incrementing minimum wage affect the employees' behaviors? Finally, to what extent the objectives of the minimum wage policy have been achieved? My passion has led me to the basic research question in Item (B), "How does the national minimum wage policy change the employers' employment strategies and employees' behaviors in Malaysia's hospitality industry?" and it has linked to my working title in Item (A). The next step is to identify the key papers in Item (C) for my research topic. The best way of filtering literature search/reading is the "cocktail glass" approach as suggested by Faff (2015). This approach proposed a wide-ranging literature search/reading and thereafter, narrow down the scope to the most relevant and important literature base. Apparently, key papers can be discerned after we have done devoted reading associated with the research topic. The papers could be influential papers that relate to your research topic or the papers that ably guides you from the theoretical framework perspectives. My key papers (Solnet et al., 2014; Ahmad et al., 2016; Repetti \& Roe, 2018) are stated in the pitch research template (see Appendix 1).

The next step is to answer the "3-2-1 countdown" in the pitching research template. The " 3 " refers to the three core aspects of empirical research project, namely ideaItem (E), data-Item (F) and tools-Item (G). This part encourages you to think deeply and to plan in detail how to conduct the research project. You need to think of the required source of data, the tools and the methodology to be used for the research project. The "2" refers to the what's new-Item (H) and so what-Item (I). I found out this is the most challenging and the most time-consuming part in the pitching research template. The what's new is essential as it inspires you to suggest the novelty of your research and to comprehend the potential contribution of your research. In fact, the "Mickey Mouse" diagram proposed by Faff (2015) is very beneficial as it clearly and effectively presents what's new in your research and the novelty of your research. I applied the "Mickey Mouse" diagram in this pitch letter to indicate the what's new and novelty of my research topic as shown in Figure 1. The intersection of these three circles represents the novelty of this research in the Malaysian context. The so what part challenges you to show why you think that your research is so important? Finally, the " 1 " refers to the contribution-Item (J), the one bottom line of the pitching research template. Generally, if you are able to successfully fill-up the what's new-Item $(\mathrm{H})$ and so what-Item (I), then you will be able to answer the contribution-Item (J). Contribution could be either or both theoretically or/and practically. 


\section{Reflections of my pitch template application}

Like many other new $\mathrm{PhD}$ students, at the initial stage of my study, I was overwhelmed with an inundation of information, but yet, I did not know what to do and where to start. Indeed, I have experienced many challenges and difficulty in developing my $\mathrm{PhD}$ research plan. Before I attended RBUS6914's class, my mindset was if one was to do a $\mathrm{PhD}$, one should craft ones ideas into a 5-10 page long so called $\mathrm{PhD}$ proposal. However, since completing this pitching class, I can confidently say that this experience has been astonishingly invaluable despite challenging. The two-page pitching template invented by Professor Robert Faff is distinctly helpful, friendly structured and concise. The thoughtful and ideally structured template provides key resources, a skeletal framework and systematic guides for any researcher, to identify and create their own the whole research plan. The template is extremely appreciated especially by a novice researcher like me. Specifically, the pitching experience trained me to be more structured in organizing my research plan, to better conceptualize and communicate my research plan in a more succinct and systematic way. Then, it gives me more confident to deliver my research in a seminar or conference setting.

Furthermore, I also learnt from my peers through the presentation sessions of their personal pitching research. It gave me more structure in crafting my personal pitch. Therefore, the pitching research has sharpened my thinking and self-development. Finally, I strongly believe that the pitching process has provided a platform of knowledge and skill to all pitchers to be successful in their research.

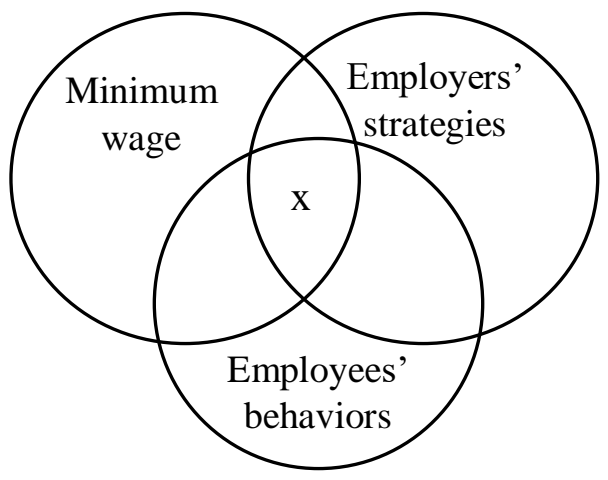

Figure 1. Mickey Mouse diagram characterizing novelty of research idea

\section{Conclusion}

This pitching research letter summarizes the experience of completing a pitching research template on my $\mathrm{PhD}$ research topic. I perceived that this pitching research 
template is a great innovation research tool in the academic world. It benefits the pitch template user in the sense that it guides user to go through the research plan, it facilitates effective communication of the core elements of research topic to the targeted audiences in a time saving manner. Given this fact, I agree strongly that this pitching research template should be recommended to new $\mathrm{PhD}$ students or novice researchers as it would benefit them, most specifically at the initial stage of their research journey. In addition, I strongly suggest they read the Faff et al.'s (2017a; 2017b) fantasy pitching papers to gain more insights and better understanding of how to apply the pitching template.

\section{References}

Ahmad, R., Scott, N. \& Abdul-Rahman, R. (2016) "Why minimum wage order implementation is a challenge to human resource managers in Langkawi hotels", International Journal of Culture Tourism and Hospitality Research, vol. 10, no.2: 191-204

Brenner, M.L. (2016) "Investigating chef-leader behavior impacts on subordinate work team identification: A pitch", Accounting and Management Information Systems, vol. 15, no.4: 826-834

Faff, R. (2015) “A simple template for pitching research", Accounting \& Finance, vol.55, no.2: 311-336

Faff, R., Ali, S., Atif, M., Brenner, M., Chowdhury, H., Crudas, L., Joubet, A., Malik, I., Nagar, V., Mi, L., Pullen, T., Siegrist, M., Smythe, S., Stephenson, J. Zhang, B. \& Zhang, K. (2017a) "Fantasy Pitching", Accounting and Management Information Systems, vol. 16, no. 2: 360-379

Faff, R., Baladi, J., Buce, D., Du Plessis, G., Du Plessis, C., Dwyer, B., Honey, K., Melton, D., Oktaviani, F., Sghen, S., Steele, L., Suhodo, D., Tanner, M., Unger, C., Wong, S., Xu, J.J. \& Zou, S. (2017b) "Fantasy pitching IV: Batman, Donald Duck, Fast Food, Superpowers, Self-Determination" (March 23, 2017). Available at SSRN: htpps://ssrn.com/abstract=2939489

Faff, R. (2018) "Pitching research", available at SSRN: http: ssrn.com/abstract=2462059 or http://dx.doi.org/10.2139/ssrn.2462059

Rad, H. (2016) "Pairs trading and market efficiency using an adaptive market hypothesis framework: A pitch", Accounting and Management Information Systems, vol. 15, no.1: 178-185

Repetti, T. \& Roe, S. (2018) "Minimum wage change effects on restaurant pricing and employment", International Journal of Contemporary Hospitality Management, vol.30, no.3: 1545-1562

Solnet, D., Nickson, D., Robinson, R.N.S. \& Kralj, A. \& Baum, T. (2014) "Discourse about workforce development in tourism - An analysis of public policy, planning, and implementation in Australia and Scotland: Hot air or making a difference?", Tourism Analysis, vol.19: 609-623 
The impacts of minimum wage on employers' employment strategies and employees' behaviour in Malaysia's hospitality industry: A pitch

Appendix 1: Completed pitching research template on "The impacts of minimum wage on employers' employment strategies and employees'

behaviour in Malaysia's hospitality industry"

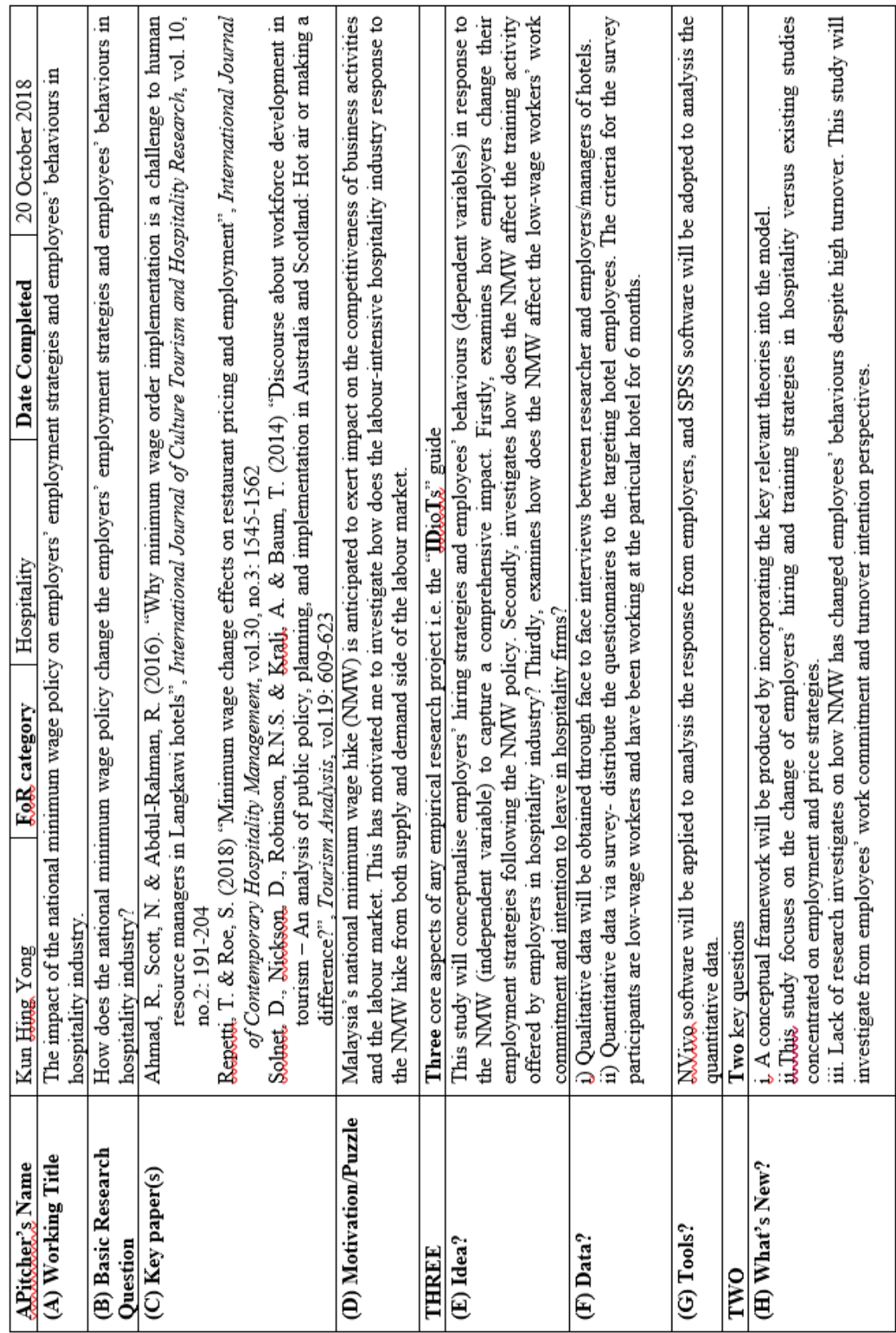

Vol. 18, No. 1 


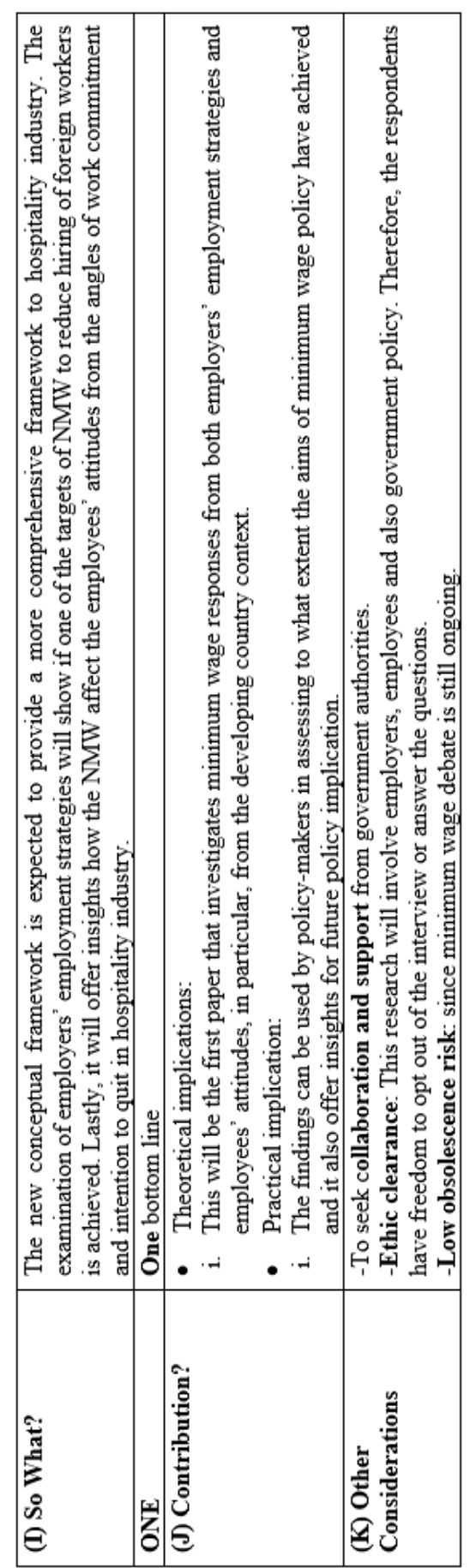

